Discussion

\title{
Pedodiversity and scaling laws: sharing Martín and Rey's opinion on the role of the Shannon index as a measure of diversity
}

\author{
J.J. Ibáñez* , S. De Alba
}

Martín and Rey (2000) agreed on the usefulness of the Shannon entropy (Shannon and Weaver, 1948) as a valuable index of diversity, which had been suggested in previous papers (Ibáñez et al., 1995a; Ibáñez et al., 1998). Their experience comes from its use as an "entropy dimension" for fractal characterisation of soil particle-size distribution (Martín and Taguas, 1998; Taguas et al., 1999). We should like to make some further points on this matter.

\section{Biodiversity-area relationships and the controversy over distribution models}

The area-species relationship (MacArthur and Wilson, 1967) has largely been corroborated by empirical data. A similar relationship has also been recognised in pedodiversity analyses (Ibáñez et al., 1990, 1995a,b; Yaalon, 1998; Phillips, 1999). In both cases, this relationship could be conformed to power laws (log series) (Ibáñez and Carrera, 1999). Since power laws are the only decreasing monotonic functions that do not vary with the changes of scale (scaling laws), many scientists are studying their relationships with fractals (e.g. Turcotte, 1992; Hastings and Sugihara, 1993). 
In several disciplines (e.g., biotaxonomy, biosystematics, ecology, human geography, pedology, fractal analysis), many data sets fit well simultaneously into several distribution models (e.g. May, 1975; Magurran 1988; Korvin, 1992; Minelli, 1993; Ibáñez and Carrera, 1999). There is a strong controversy arising from the simultaneous fits of the same data sets to both lognormal and power law distribution (Magurran, 1988; Korvin, 1992; Solé and Manrubia, 1996).

Basically, the origin of this problem is due to statistical procedures and sampling methods. Much of the criticism on the goodness-of-fit tests arises from the failure to provide a clear distinction between competing distribution models (Magurran, 1988; Korvin, 1992; Turcotte, 1992). On the other hand, the impossibility of embracing all taxonomic diversity in any sampling scheme, restricted in space and in time, gives rise to many "rare" or infrequent taxa not being gathered or identified. In consequence, the figures of diversity indices, as well as the fits to different distribution models, could be biased (Preston, 1948; Taylor, 1978; Magurran, 1988). Several studies provide strong support for the adoption of power laws instead of lognormal distributions in these frequent situations (Taylor, 1978; Hughes, 1986; Korvin, 1992). What we actually observe to a large extent depends on the way of sampling and conceptual assumptions (Ibáñez and Carrera, 1999).

\section{Diversity, power laws and fractals}

Assuming the above observations, is not surprising that the $\alpha$-statistics of the logarithmic series and the $\lambda$-statistics of the lognormal have also been used as diversity indices (Magurran, 1988). The $\alpha$-statistics discriminate better than $\lambda$-statistics (Southwood, 1976; Taylor, 1978). Together with the Shannon index, the former are often estimated (Magurran, 1988). Since the $\alpha$-statistics proves to be the exponent of its corresponding power law, its relation with the fractal dimension is more or less clear. For some experts in fractals, the detection of power laws (which, as we have seen, is not trivial) is a clear proof of the existence of fractal structures (Turcotte, 1992). If this is so, the estimates of diversity, via $\alpha$-statistics (when the data sets conforms to log series) would seem to reflect underlying fractal properties.

The most important fractal dimensions are the Kolmogorov capacity $D_{\mathrm{c}}$, the Hausdorff dimension $D_{\mathrm{H}}$, the correlation dimension $D_{\text {corr }}$ and the information dimension $D_{\mathrm{I}}$ ( see Korvin, 1992). Information entropies have been also used in soil science to parametrize fractal distributions (e.g., Martín and Taguas, 1998). For example, $D_{\mathrm{I}}$ measures how many bits of information are needed to specify a point of the fractal with a given accuracy. Thus, $D_{\mathrm{I}}$ measures the increasing rate of the information entropy (via Shannon formula) when the accuracy (scale) at which it has been evaluated increases (see Korvin, 1992; Martín and Taguas, 1998). 


\section{Fractals, statistical and thermodynamic relationships}

Pastor-Satorras and Wagensberg (1996,1998), among others, use the Principle of Maximum Entropy (MaxEnt Principle) for the study of fractal sets. This Principle states that: "The least biased and most likely probability assigmnent (the structural distribution $p\left(X_{i}\right)$ ) is that which maximises the total entropy subject to the constraints imposed on the system" (Jaynes, 1957). The total entropy could be estimated via the Shannon formula. Besides the trivial normalisation condition of equiprobability: $E=H / H_{\max }=1$ ( see Ibáñez et al., 1995a,b, 1998), the additional constraints imposed on the system (the global effects of the physical laws involved) may be mathematically solved. Thus, the MaxEnt Principle allows a novel statistical characterisation of fractal objects and dimensions (Pastor-Satorras and Wagensberg, 1996, 1998).

\section{From pedodiversity to pedocomplexity indices}

Can the Shannon index be used as a measurement of complexity? The answer is no despite the fact that this comparison has been done frequently (Solé and Manrubia, 1996). If richness offers a measurement of the number of different objects of a given system, diversity estimates the distribution of structural probabilities. However, none of the two provides the way in which different parts of the system are related to each other, i.e., their "connectance". There is an empirical negative relation (power law) between diversity and connectance (Pimm, 1982; May, 1983). Thus, as the number of different objects in a system increases, it becomes necessary that the relation between the objects be less rigid (Margalef and Gutiérrez, 1983). A measurement should be introduced that accounts for the degree of interaction between its parts in order to describe the complexity of a system. For some authors (Li, 1990; Solé and Manrubia, 1996), the best candidate for estimating a system's complexity would be an algorithm accounting for the mutual information of its elements. In its simplest form, for two variables, $X$ and $Y$, the mutual information or joint entropy, i.e., that associated with their respective probabilities $A$ and $B$ is:

$$
I(X, Y)=-\sum_{j=1}^{m} \sum_{i=1}^{n} P\left(A_{i}, B_{j}\right) \log \left[P\left(A_{i}, B_{j}\right)\right]
$$

where $P\left(A_{i}, B_{j}\right)$ is the joint probability of the pair of variables, or the information provided on $X$ by $Y$ (see Solé and Manubia, 1996 and references therein). In short, the interrelationships between diversities, entropies and fractals appear to be a fruitful line for future soil research.

\section{References}

Hastings, H.M., Sugihara, G., 1993. Fractals: a User's Guide for the Natural Sciences. Oxford Univ. Press, NY, 235 pp. 
Hughes, R.G., 1986. Theories and models of species abundance. Am. Nat. 128, 879-899.

Ibãñez, J.J., De-Alba, S., Bernúdez, F.F., García-Álvarez, A., 1995a. Pedodiversity: concepts and tools. Catena 24, 215-232.

Ibáñez, J.J., De-Alba, S., Boixadera, J., 1995b. The pedodiversity concept and its measurement: application to soil information systems. In: King, D., Jones, R.J.A., Thomasson, A.J. (Eds.), European Land Information System for Agro-Environmental Monitoring. JRC, EU, Brussels, pp. 181-195.

Ibáñez, J.J., De-Alba, S., Lobo, A., Zucarello, V., 1998. Pedodiversity and global soil patterns at coarser scales (with Discussion). Geoderma 83, 171-214.

Ibáñez, J.J., Carrera, C., 1999. Diversity and Scaling Laws. International Workshop on Chaoric Dynamics and Fractals in Geosciences. E.T.S.I. Agrónomos, Madrid, (September 14-17), Madrid (dissertation).

Ibãñez, J.J., Jiménez-Ballesta, R., García-Álvarez, A., 1990. Soil landscapes and drainage basins in Mediterranean mountain areas. Catena 17, 573-583.

Li, W., 1990. Mutual information functions versus correlation funct J. Stat. Phys. 60, 823-829.

Jaynes, E.T., 1957. Infornation theory and statisal mechanics. Phys. Rev. 106, 620-630.

Korvin, G., 1992. Fractal Models in the Earth Sciences. Elsevier, Amsterdam, 396 pp.

MacArthur, R.H., Wilson, E.O., 1967. The Theory of Island Biogeography. Princeton Univ. Press, Princeton, 203 pp.

Magurran, A.E., 1988. Ecological Diversity and Its Measurement. Princeton University Press, Princeton, 179 pp.

Margalef, R., Gutiérrez, E., 1983. How to introduce connectance in a frame of an expression for diversity. Am. Nat. 121, 601-607.

Marín, M.A., Taguas, F.J., 1998. Fractal modelling, characterization and simulation of particle-size distribution in soil. Proc. R. Soc. London A 454, 1457-1468.

Martin, A.M., Rey, J.-M., 2000. On the role of Shannon's entropy as a measurement of heterogenity. Geodernna 98, 1-3, (this issue).

May, R.M., 1975. Patterns of species abundance and diversity. In: Cody, M.L., Diamond, J.M. (Eds.), Ecology and Evolution of Communities. Harvard Univ. Press, Cambridge, MA, pp. 81-120.

May, R.M., 1983. [Review of] food webs. Science 220, 295-296.

Minelli, A., 1993. Biological Systematics. The State of the Art. Chapman \& Hall, London, 387 pp.

Pastor-Satorras, R., Wagensberg, J., 1996. Branch distribution in diffusion-limited aggregation: a maximum entropy approach. Physica A 224, 463-479.

Pastor-Satorras, R., Wagensberg, J., 1998. The maximum entropy principle and the nature of fractals. Physica A 251, 291-302.

Phillips, J.D., 1999. Earth Surface Systems. Blackwell, Oxford, 180 pp.

Pimm, S.L., 1982. Food Webs. Chapman \& Hall, London, 219 pp.

Preston, F.W., 1948. The commonness and rarity of species. Ecology 29, 254-283.

Shannon. C., Weaver, W., 1948. The Mathematical Theory of Communication. Univ. Ilinois Press, Urbana, IL, $117 \mathrm{pp}$.

Solé, R.V., Maurubia, S.C., 1996. Orden y Caos en Sistemas Complejos. Ediciones UCP, Barcelona, 595 pp.

Southwood, T.R.E., 1976. Ecological Methods. Chapman \& Hall, London.

Taguas, F.J., Martín, M.A., Perfect, E., 1999. Simulation and testing of self-similar stuctures for soil paricle-size distributions using iterated function systems. Geoderna 83, 171-192.

Taylor, L.R., 1978. Bates, Williams, Hutchinson - a variety of diversities. In: Mound, I.A., 
Warloff, N. (Eds.), Diversity of insect Faunas: 9th Symposium of the Royal Entomological Society. Blackwell, Oxford, pp. 1-18.

Turcotte, D.L., 1992. Fractals and Chaos in Geology and Geophysics. Cambridge Univ. Press, Cambridge, $210 \mathrm{pp}$.

Yaalon. D.H., 1998. Pedodiversity and global soil patterns at coarse scales. Geodernna 83, 193-196, In discussion of: J.J., Ibáñez, S., De-Aba, A., Lobo, V., Zucarello. 